\title{
RSL e - textbook as Integral Part of Interactive Educational Environment of Modern University
}

\author{
Valentina Mordvintseva, Nadezhda Nikulina*, and Elena Proudchenko \\ Sciences, Department of international communication Tyumen Industrial University, Tyumen, Russia
}

\begin{abstract}
The article presents the foundation for the $\mathrm{e}$ - textbook developing speaking skills of foreign students studying Russian at the pre-University training courses. Since the current level of the information and communication technologies development is focused on the real educational practice of specific educational institutions, there is a need to create original electronic learning tools, especially e - textbooks, which form the basis of the virtual educational environment of the University. The article demonstrates the advantages of an $\mathrm{e}$ - textbook combining the academic content organization with the efficiency and accessibility of modern information and communication technologies. It is noted that the newest methods of material supply expand significantly the didactic potential of the textbook, making it an effective means of formation of students' communicative competence. In addition, the principles of organization and the e textbook content components, based on regionally oriented materials, correspond to modern strategies of foreign students' adaptation to the particular Russian University and city conditions.
\end{abstract}

There is no doubt that the theory of methodological research is often based on experience, which is influenced by a variety of factors. Scientific researches on the quality of textbooks for foreigners are diverse in content and value. Only under the aegis of the Russian Association of teachers of the Russian language and literature and with the support of the Fund "Russian world», about twenty conferences devoted to actual problems of teaching Russian as a second language are held annually. Representatives of numerous universities share their experiences and discoveries with each other. Scientific research in the field of methodology of teaching RSL encourages professionals to create textbooks for foreign students with different levels of language proficiency. And herewith the widespread increase in the number of foreign students in Russian universities contributes to the fact that publishing activities in this direction are activated not only in the capital's universities, but also in the peripheral, which do not have long-standing traditions in teaching Russian as a foreign language. Among such universities is Tyumen industrial University. But meanwhile there are very few textbooks on the speaking skills development and such textbooks are focused on living conditions in a particular city and University. Working with them is possible, but requires constant adjustments to the realities of life a particular city. In addition, often the Russian text is duplicated in English, which is not always convenient for teachers working with students who do not speak English. Additional inconvenience factors are as follows: overprices for modern textbooks, difficulties in replicating materials, the difference in logic of the grammar course presentation, etc. Working with e publications or training resources that are in site availability is different. But in this case, an experienced teacher tries to collect the training materials on his/her own, and is often forced to develop individual projects. Modern technologies in teaching Russian as a second language in various aspects become the object of scientific understanding in I. I. Kalinina, N. E. Popov, Yu. Kobenko, I. Y. Nizovaya and others' studies. In particular, the key idea is that the current level of information technology development raises the question of creating a new learning environment, infrastructure that meets the needs of the time [1]. Therefore, each University interested in attracting foreign students faces the need to create a system of educational offers on the RSI by means of a website and even distance teaching and is forced to stimulate the original textbooks and programs creation that reflect the level of ICT development.

In educational practice, changes caused by intensive development of information technologies concern first of all the basic training tool which is the textbook: "the classic paper textbook is replaced by an electronic textbook, which is considered as one of the necessary content components of the interactive educational environment of a higher educational institution" [2]. The composition and principles of the development of such educational tools, their role in creating conditions for the individualization of the educational process due to the diversity of forms of representation of educational content are actively discussed in the modern methodological literature; principles of interaction

Corresponding author: nadya-nika2006@yandex.ru 
between the user and the ICT tool [3-5]. At the same time, experts in the field of teaching RSL consider the methods of the learning material presentation, namely the synthesis of various forms, including not only text and graphics, but also animation, audio and video resources to be undeniable advantage of the electronic textbook. The textbook is a traditional genre possessing conceptual completeness, which makes it a multifunctional and at the same time systemic educational resource. It is about the integration of traditional approaches and the latest technological capabilities presented in the electronic textbook which N. Ye. Popova and O. A. Chikova write about. They think, this "allows using of the textbook in various forms of education, including distance learning, which is widely demanded at the present time" [6]. In our opinion, the ability to organize students' extracurricular work in modes convenient for young users of modern gadgets is an additional advantage. I. Grabar and T. Galavash in their works point this opportunity as a strong prospect of the electronic textbooks use in teaching Russian as a second language: "e - textbooks require the same technical means that students use to communicate outside the educational process, which increases the motivation to achieve mastery of course posted on electronic media" [7].

Currently, there are various types of information and communication technologies focused on language learning, including Russian as a foreign language. All possibilities are well known to practitioners and consistently presented in I. Yu. Nizova's article as: "e textbooks, interactive training simulators, virtual environments (virtual museum, virtual travel), computer presentations, electronic texts databases, exercises, reference and information sources (online translators, dictionaries), e - libraries, electronic collections (collections of audio, photo and video files), web applications to textbooks, means of communication in social networks, etc." [8]. All these materials can be used by the teacher and recommended to students as a source of information, independent work on listening, vocabulary semantics, expansion of vocabulary in the field of the studied language, of grammar skills development. The e - textbooks development is also taken into account. Of course, there is a need to constantly adapt already existing resources in accordance with the logic and methodology of teaching a particular aspect of the Russian language as a second language and leading competencies. As a result, writing own didactic means focused on concrete audience and available technically.

Improvement of educational space in teaching RSL at Tyumen Industrial University, the use of modern elearning modalities leads to designing e-textbooks as important components of an interactive educational environment.

The e - textbook is usually considered as computerbased training system including didactic, methodical and information and reference materials in various academic disciplines, as well as software. It allows combining them to gain knowledge and controlling academic and educational achievements. E. G. Azimov and A. N.
Shchukin define the e-textbook as "a software and methodological complex combining a printed text, a multimedia component (video, animation, audio files), a workshop (exercises, test questions and tests), statistics of completed tasks and exercises, statistics of learning time, an electronic dictionary, built-in directories, a remote support unit" [9]. It means that the RSL e textbook development involves the interaction of the content of the textbook and the technical means by which the content will be placed in the shell, in the desired type of a program. This e - textbook development involves equal participation of a RSL teacher and a specialist in modern communication technologies. Accordingly, when developing an etextbook, questions concerning its structure, methods of content organization and the learning material presentation will be essential.

The specific features of foreign languages teaching, including Russian as a second language, involves the use of related sources (dictionaries, phonetic applications, etc.), which would make the use of hypertext forms in the organization of information highly important. It is the hypertext which allows one to quickly move from one section to another, from one type of information to another, to search for it. An example of such an etextbook is a course "Time to speak Russian", developed by the Center for International Education of Moscow State University supported by the "Russian world" Fund [10].

When developing the concept of a regionally oriented textbook for the speech development (elementary and basic levels of the Russian language) we take into account the linguistic and methodological requirements for the content management of the e-textbook. In the textbook "My life in Tyumen» speech environment is didactically inherent in the content of the topics. The didactic components of the e-textbook make it possible to turn this learning tool into an effective element of the educational space. The environmental approach to the theory and methodology of teaching foreign languages is considered to be the key of any learning processes modeling. Foreign students studying Russian "from scratch" at the pre-University training courses, even while in the country of the studied language, cannot fully use the natural communication resources due to the lack of theoretical training and communication skills. As Yu. V. Kobenko writes, "at this stage of language development, the lack of habit to use another unfamiliar nomination system with its features is overcome through artificial modeling of the" speaking" environment best of all" [11]. The e-learning tool can serve precisely these purposes because it differs favourably from the usual means of learning by its multidimensional nature.

The list of topics under consideration is typical for the elementary and basic levels of RSL. The difference is in the regional specificity, designed to develop the competence, important for communication in Tyumen and Tyumen University, where the student plans to continue studying. For example, in the topic "Food" the educational block is formed taking into account the realities of student's life in Tyumen. The following is one of the reference texts: 
Where to buy food in Tyumen?

In Tyumen in recent years, many shops have appeared where you can buy food. These are very different stores. First, there are different supermarkets. Cheap or, as it is written in advertising, "economical" supermarkets like "Magnit" or "Monetka". Megamarkets such as "Auchan" and "Lenta" are popular in Tyumen. In these stores, there is a diverse selection of products and, as a rule, at a low price.

Secondly, the old Tyumen markets continue to work. Fresh vegetables and fruits, as well as fresh meat, can be bought at the market. And at the market you can buy Russian traditional products like pickles and sauerkraut.

Third, small shops remained in Tyumen. They are usually located on the ground floors of blocks of flats. Products there are usually more expensive than in supermarkets. But these shops are close to home, and people like to go shopping there.

Students of Tyumen industrial University often go to the "Mostovsky" store, because it is located in the campus area. There they buy the most necessary goods. On weekends, students buy food in the Tyumen hypermarkets. This way they save their money.

But some people almost never go shopping, and order food on the phone or Internet. It is more expensive, but very convenient.

Questions to the text:

1. What supermarkets are there in Tyumen?

2. What stores do the students of Tyumen oil and gas University go shopping to?

3. What products do you buy every day or very often?

4. Do you order food by phone or Internet? Why?

The text contains hyperlinks to the Tyumen shops photos, accompanied by questions and related dialogues (dialogues are texted and sounded). And all other topics are presented in a similar way in the e-textbook. For example, the topic "At the doctor's" contains vital information about receiving medical care in the campus and in Tyumen.

The use of regional materials in the didactic process of linguistic and cultural potential can be considered as one of the ways to activate the communicative component in the RSL class when developing the relevant competence. This includes "normative knowledge of the language units semantics at different levels, mastering the mechanisms of constructing and paraphrasing statements, the ability to generate discourse of any length, in accordance with the cultural and speech situation which includes the parameters of the addressee, place, time and conditions of communication" [12].

The e-textbook with a hypertext structure includes units containing, as already noted, texts-speech samples corresponding to a certain level of the language proficiency. When creating a text which can be effectively used in teaching Russian as a second language, it is necessary to take into account many factors: it should be a text with culturally relevant information, also it should be understandable to foreign students of a certain level of education. The grammatical accuracy of the text and its units deserves close attention, since any use of the text as a communicative activity stimulus should be accompanied by the grammatical skills development and in general by the "linguistic consciousness, one of the components of cognitive consciousness that provides such kind of activity as use of speaking skills" [13]. The level of grammatical difficulty and types of grammatical structures fixed in the text are determined by the specifics of the topic. Thus, it is impossible to discuss the topic "A stroll through Tyumen" without a grammatical support, namely, without learning verbs of motion in the Russian language.

Texts are accompanied by a system of tasks aimed to prepare students for the text perception, identifying the level of the text understanding, reproducing its content, building their own statements based on the text. Creative tasks make students tell about facts from their city life, life of their neighbourhood, etc. When doing such tasks students are aware of the specific Russian culture and their national culture. For example, after exploring the streets of Tyumen, students are invited to talk about their favorite street in their hometown. Thus making such story has been prepared by the previous tasks and, as a rule, does not cause serious difficulties as necessary grammatical and syntactic patterns have been preliminary worked out, the vocabulary has also been revised. It is important to note that the choice of topics which are close to foreigners such as hometown, home, neighbourhood, favorite food, etc. helps in communication skills development, motivates their learning attitudes. At the same time, the local lore content of the texts reflects the real sociocultural conditions of teaching foreign students. It also helps to the successfully adapt students to the country of the language studied. The presentation of the teaching material is accompanied by voiced dialogues, which are one of the resources of the so-called "communication fund" for RSL students. They contain all prosodic phenomena: the phrase intonation, verbal stress, the pause type and its semantics. T. M. Nikolaeva writes about the effectiveness of such material in mastering Russian as a second language [14]. Speech situations are supplemented by a video showing typical communicative situations, serving as the ground to communicative oriented tasks.

A significant advantage of the e-textbook is the possibility to include authentic texts into the students' didactic field (videos from training sessions, gym, student cafe, etc.). It is the real speech situations and educational dialogues that allow us to improve the speakers knowledge about the stylistic diversity of Russian speech, the Russian language varieties, and mainly about the oral speech, which differs significantly from the written speech used in the "educational language" in the majority of RSL textbooks. The importance of live speech development is not in doubt [15], but in fact it is difficult to achieve positive results working with paper textbooks. Mastering live speech in the format of linear (paper) textbook can be implemented in the least.

The foreigners studying Russian language at the preparatory Department will be participants of student's discourse having its own peculiarities. The article by E. 
V. Ivantsova and E. V. Chernykh refers to violations of the speech behavior norms in student communication, which, according to researchers, may cause conflicts [16]. The reaction of foreigners to the speech of Russianspeaking students, adequate to the communicative event is an important adaptive skill. Accordingly, a teacher of RSL must understand that the students' speech is characterized by the use of slang, reduced vocabulary and precedent texts, as well as creativity, including games, the desire to make their speech colourful, bright, unusual. We tried to reflect all these in dialogues and communicative situations presented in the e-textbook. One of its purposes is to integrate a certain social group into the communicative space and to understand the basic features of the Russians' communicative behavior.

The dictionary is one of the necessary components of the e-textbook on the speech development, and in contrast to the paper textbook, it may include visual means of semantic vocabulary. The possibility of creating a dictionary in an e-textbook as a separate block of information requires finding criteria for the selection of lexical units in accordance with the educational lexicography traditions, lexical units were selected on the their communicative relevance basis (semantic importance; usage within the given list of pre-selected topic vocabulary; compliance with the most significant communicative intentions) [17]. They are characterized by a number of features, such as semantic value, which denote important socio-cultural concepts, make up the language lexical core; the ability to word-formation relations; the ability to be included in the phrase; stylistic neutrality; frequency of use in speech and in RSL textbooks [18]. These principles of lexical material selection are implemented in the "Basic Russian vocabulary" corresponding to a certain level of proficiency in Russian as a second language and taken as a basis for the vocabulary as the e-textbook content component. The training part of the e-textbook provides various exercises, primarily aimed at the development of communication skills such as narration, text reconstruction, the creation of a dialogue based on the text, text compression on semantic grounds and on formal features. Knowledge and skills gained in the Russian language classes are practiced and activated in self-learning work with e-textbook and those Internet teaching resources which are referred to in the study topic.

Tasks intended for students ' self-learning work can be of different degree of complexity and focus. Working with the e-textbook can help to study the new material and solidify the knowledge. Such tasks examples are contained in all the units of the e-textbook. Often tasks for self-learning work are to be done in the same way as those which have been analyzed in class.

Here are examples of a few similar tasks in the unit "A stroll through Tyumen" showing the possibility of RSL e-textbook.

Listen to the text (a hyperlink to the audio text is given).

Questions for listening tasks:

1. What's the student's name?

2. Where does he study?
3. What country did he come from?

4. What kind of profession does he want to get?

5 . Where is he going now?

6. What does he say about the Republic Street?

Read the text.

Tyumen industrial University

I came from Yemen. My name is Ammar. Now I study at the preparatory Department of the Tyumen industrial University. I'm going to the international Department now. It is located in the main building of the University. It is in the city center, near the Central square.

I am going along the main street of Tyumen. The Republic street is the most beautiful street. I often go here because I like to walk around the city. I see the building of the regional library, the bus station "Nemtsov public garden" and the monument to the famous oilman Yuri Erve. I want to be an oilman too. I have approached the University building. It's beautiful! I am glad that now I am studying in the city, which is called the oil capital.

Do the task:

1. Using the map (a hyperlink to the city map is given), find a place a student from Yemen is talking about. What building is next to the main building of the Tyumen industrial University? How to get from the hostel on Melnikaite street to the main building?

2. Retell the text using the verbs in the past tense. The beginning of the retelling should be: "Yesterday a student from Yemen Ammar was in the international Department. ..."

3. Why is Tyumen called the oil capital?

Additional task.

1. Look at the photo (a hyperlink to the photo is given). It shows a monument to the famous oilman. Describe it.

2. Prepare a story about the monuments that are in your hometown (in the country).

3. Come up with an unusual monument model and describe it: a) a monument to the diligent student; b) a monument to a grandmother; C) a monument to the teacher of the University; d) a monument to books that are not read by anyone; d) a monument to the Internet; etc.

Listen to the text (a hyperlink to the audio text is given).

Questions for listening tasks:

1 . What's the student's name?

2. What country did he come from?

3. Where is his students' residence?

4. Does he go to the University on foot or by bus?

5. In which academic building of the University does he study?

Read the text.

Sadat is speaking about Tyumen

I'm Sadat. I came to Tyumen from Ghana. Now I know what Siberian frosts are. I have been living in Tyumen for the third year, so I'm used to the cold climate. I am not afraid of cold, because I live in a warm cozy hostel on Melnikaite street.

It's a campus. Here are the dormitories of all the main universities of Tyumen. Every day I go to the University on foot. I walk down the Melnikayte street past the city 
hospital, I go to the store, buy juice and move on. On the territory of the hospital there is a Church. I like to look at this temple and think of loved ones. I cross the street at a pedestrian crossing near the roundabout. And here is our new building number 7 . It is a modern building where students from different countries study. Yes, I like to live and study in this city.

Do the task:

1.On the map find the place which the student from Ghana is speaking about. Show on the map what is located next to the building in which Sadat is studying. Tell about these places.

2. Tell what street you live on now. Describe your way to the University.

Additional task.

Watch the video prepared by University students (hyperlink on the video is given) and answer the following questions:

1. Where are students going to?

2. Where do they study?

3. Near what building of TIU have they stopped?

4. Why do they like Melnikaite street?

Listen to the text (a hyperlink to the audio text is given).

Questions for listening tasks:

1. Как зовут студента?

2. Как долго он живёт в Тюмени?

3. Где он был вчера?

4. С кем он был там?

5. Какую музыку он любит?

Read the text.

Kelvin gets to know Tyumen

I live in Tyumen. I'm Calvin. I have been living in Tyumen for the third year. I already know the city center, where the administrative building of the Tyumen industrial University and the international Department are located, very well. I often walk with my friends along the Republic street to the bridge of Lovers.

I like Tyumen. This is both the old city and the new one simultaneously. In Tyumen there are old buildings, which are more than a century old, and modern avenues with bright advertising. I've already been to the local history Museum. It is opposite the bridge of Lovers. We went to other museums in Tyumen, but only yesterday I learned new Tyumen that is theatrical Tyumen.

My friend Sharon and I went to the theater yesterday. The performance was very interesting, but I liked not only the performance. The theater building is the beauty of the city. After the performance we were taking pictures against the building. And then we had a long walk around the city. Next weekend we will go to the Philharmonic. I don't really like classical music, but Sharon likes classical music. It seems to me that the Philharmonic is located near the main building, also on the Republic street. Today I will look at the city map, where the Philharmonic is located and how to get there.

Do the task:

1. On the map find places which the student is telling about. On the map show how to walk (or get) to the theater and to the Philharmonic from the bus station "Nemtsov public garden". Describe your route.

2. Put the words in brackets in the desired case.
I was (local history Museum). The Philharmonic is located (Republic street). Next weekend we will go to (Philharmonic).

3. Watch the video prepared by students of the University (hyperlink on the video is given) and answer the following questions:

1. Where are the students?

2. What are they doing?

3. What do they like and what do they dislike?

End-of-unit test (for self-learning)

1. On the maps describe the following routes:

1) from the students' residence to the Bank ("ZapsibkomBank»);

2) from the University to the local history Museum;

3) from the students' residence to the clinic.

2. Prepare a video report from the place you like in Tyumen more than others, explain the reasons for your sympathy.

On the one hand the above-mentioned e-textbook unit clearly demonstrates the methodological capabilities of such project. On the other hand, it shows its special motivating focus. It is the interest in the language, the city, people, creative attitude to work that leads to the pedagogical success, which the authors of this etextbook remember and actively use in their teaching activities.

Thus, the e-textbook "My life in Tyumen" is

1) an integral part of electronic (virtual) educational environment of Tyumen industrial University and takes into account such peculiarities of the Russian language teaching at University as student population, their education and living conditions, communicative preferences, etc.;

2) a comprehensive project combining traditional methods of organizing the textbook contents with the advantages of modern information and communication technologies presented in the learning electronic resources;

3) a learning process component, able to intensify the students' activities, to raise their self-learning level in the didactic process, to develop self-control skills;

4) a form of the material presentation fit to the time requirements and based on audio and video files, encouraging foreign students to speak spontaneously in a certain communicative situation, ensuring the auditive skills development;

5) a factor of successful adaptation of foreign students in the University, city and country, increasing interest in the realities of a new life, motivating their communicative success.

\section{References}

1. I. I. Kalinina, Educational Studies 3, 5-32, (2005)

2. E. A. Spirina, D. A. Kazimova, S. A. Mulikova, NSPU Bulletin 7, 4, 27. (2017)

3. N. E. Popova, NSU Bulletin 3 (25), 34-44, (2015)

4. N. R. Dobrushina, A. I. Levinzon, Educational Studies 4, 163-169, (2006) 
5. T. Je. Sizikova, N. A. Stunzha, A. F. Poveshhenko, R. O. Agaveljan, T. V. Voloshina, NSU Bulletin 7(6), 71-86, (2017)

6. N. E. Popova, O. A. Chikova, NSU Bulletin 2(18), 23, (2014)

7. I. Grabar, T. Glavash, IKT, NSU Bulletin 4(32), 54, (2016)

8. I. Ju. Nizovaja, Siberian pedagogical journal 5, 51, (2012)

9. Je. G. Azimov, A. N. Shhukin, A new dictionary of methodological terms and concepts. Theory and practice of teaching (M.: IKAR, 2009)

10. A. Ju. Petanova, Ju. E. Kovalenko, Time to speak Russian! Center for International Education Institute of Russian Language and Culture of Moscow State University named after MV Lomonosov. Lomonosov Moscow State University, 2005-2013, URL: https://yandex.ruspeakrussian.cie.ru. html (date of access: 16.03.18)

11. Ju. V. Kobenko, Tomsk Journal LING \& ANTHRO 2 (16), 41, (2017)

12. E. N. Franceva, O. S. Prilepskih, E. N. Kuznecova, A. V. Doncov, S. G. Korljakova, NSPU Bulletin 7(4), 117, (2017)

13. I. A. Sternin, Journal Logos 4(49), 160

14. T. M. Nikolaeva, Issues in Linguistics 4, 15, (2015)

15. A. Mustajoki, Issues in Linguistics 5, 15, (2013)

16. E.V. Ivancova, Z.V. Chernyh, TSU Bulletin, Philology 5(43), 32, (2016)

17. G.F. Bogachjova, V.V. Morkovkin, TSU Bulletin, Philology 3(15), 8, (2011)

18. R. Jadav, N. G. Nesterova, K. S. Verma, Journal of lexicography 12, 108, (2017) 